\title{
Carburization induced extra-long rolling contact fatigue life of high carbon bearing steel
}

Cao, Zhaoxi; Liu, Tianqi; Yu, Feng; Cao, Wenquan; Zhang, Xiaodan; Weng, Yuqing

Published in:

International Journal of Fatigue

Link to article, DOI:

10.1016/j.ijfatigue.2019.105351

Publication date:

2020

Document Version

Peer reviewed version

Link back to DTU Orbit

Citation (APA):

Cao, Z., Liu, T., Yu, F., Cao, W., Zhang, X., \& Weng, Y. (2020). Carburization induced extra-long rolling contact fatigue life of high carbon bearing steel. International Journal of Fatigue, 131, [105351].

https://doi.org/10.1016/.ijfatigue.2019.105351

\section{General rights}

Copyright and moral rights for the publications made accessible in the public portal are retained by the authors and/or other copyright owners and it is a condition of accessing publications that users recognise and abide by the legal requirements associated with these rights.

- Users may download and print one copy of any publication from the public portal for the purpose of private study or research.

- You may not further distribute the material or use it for any profit-making activity or commercial gain

- You may freely distribute the URL identifying the publication in the public portal 


\title{
Carburization induced extra-long rolling contact fatigue life of high carbon bearing steel
}

\author{
Zhaoxi Cao ${ }^{\mathrm{a}}$, Tianqi Liu ${ }^{\mathrm{b}}$, Feng $\mathrm{Yu}^{\mathrm{c}}$, Wenquan $\mathrm{Cao}^{\mathrm{c} *}$, Xiaodan Zhang ${ }^{\mathrm{d} *}$, Yuqing \\ Weng ${ }^{\mathrm{c}}$
}

a. Science Faculty, University of Sydney, NSW2006, Australia

b. Institute of Aeronautical Materials, Beijing 100095, China

c. Central Iron and Steel Research Institute (CISRI), Beijing 100081, China

d. Section of Manufacturing Engineering, Department of Mechanical Engineering, Technical University of Denmark, $2800 \mathrm{Kgs}$, Lyngby, Denmark

*Corresponding author: Wenquan Cao (caowenquan@nercast.com), Xiaodan Zhang (xzha@mek.dtu.dk)

\begin{abstract}
For the first time, vacuum carburization surface treatment was applied to high carbon bearing steel 100Cr6. The rolling contact fatigue (RCF) life and the wear behavior of $100 \mathrm{Cr} 6$ with and without carburization were compared and the microstructure was characterized. The carburization results in 30 vol.\% cementite and $\sim 20$ vol. \% retained austenite in the surface layer, significantly higher than those processed by the conventional heat treatment. RCF life (L10) is significantly enhanced by more than 10 times from $1 \times 10^{7}$ cycles to $\geqslant 1 \times 10^{8}$ cycles by carburization. This enhancement is attributed to plate/rod cementite and retained austenite.
\end{abstract}

Key words: Vacuum carburization; High carbon bearing steel; Rolling contact fatigue; Coefficient of friction; Gradient distribution of carbides

\section{Introduction}

Bearing is one of the components widely used in our daily lives and industry, such as the airplane, the ship, the automobile and the machining tools with a high turning 
speed and high accuracy [1-3]. The bearing steel can be divided into two distinct categories[4-5]. One is the surface hardened $(\mathrm{CH})$ bearing steel with carbon content about $0.10-0.20 \%$, such as the $20 \mathrm{CrNi} 2 \mathrm{Mo}$ (AISI4320) steel, which needs to be carburized to increase the surface hardness up to no less than $58 \mathrm{HRC}$ with carbon content increasing up to $0.65-1.1 \%$ in the carburized surface layer $[4,6]$. The other is the through hardening $(\mathrm{TH})$ bearing steel with carbon content around $0.9-1.1 \%$, such as the 100Cr6 (AISI52100) steel, which is normally heat treated by quenching and tempering to get a bulk hardness of no less than 58 HRC. Previous investigations have shown that the life factor (LF) of the surface hardened bearing steel is significantly higher than that of the through hardening bearing steel due to the higher compressive residual stress in the surface layer. The high surface residual compressive stress and the higher surface hardness result in a higher RCF life [6,7]. Recently, much effort have been put on the TH bearing steel to increase the RCF by heat treatment [8-10]. It was reported by the SKF company that for the TH bearing steel increasing the surface hardness with about 1-2 HRC could increase the RCF life up to 2 times, indicating an important role of surface hardness to increase the RCF life of the TH bearing steel [6]. It was also demonstrated that the RCF life $\left(\mathrm{L}_{10}\right)$ could be significantly increased by 5 folds by the refinement of both prior austenite grain size and the carbide size $[8,11]$. In addition, As the introduction of the retained austenite in the surface layer is beneficial to the rolling contact fatigue life, the maximum enhancement of the rolling contact fatigue life could be realized when increasing austenite volume fraction from 7 vol. \% to 50 vol. $\%$, resulting in 10 times' enhancement of rolling contact fatigue life 
[12]. Although it has been proved by many researchers that the carburization is effective to increase the surface residual compressive stress, the surface hardness and the residue austenite volume fraction [13-15], this type of surface treatment technology has never been applied in the $\mathrm{TH}$ bearing steel and no microstructure evolution has been reported in literature [16].

In light of the higher RCF life of the $\mathrm{CH}$ bearing steel, the carburization of the $\mathrm{TH}$ bearing steel of $100 \mathrm{Cr} 6$ was carried out in this study. The comparison of the RCF life of $100 \mathrm{Cr} 6$ with and without carburization was performed. The microstructure and the surface hardness after carburization process were examined and analyzed. The formation mechanism of the surface carbides and the enhancement of the RCF life were discussed. Our aim is to reveal the possibility to increase the RCF life of the TH bearing steel by carburization.

\section{Material and methods}

The high carbon bearing steel of 100Cr6 with nominal chemical composition of 1.05 wt.\% $\mathrm{C}$ and 1.42 wt.\% $\mathrm{Cr}$ was fabricated by the second refining, continuous casting $(\mathrm{CC})$ and hot rolling, and finally rods with a diameter of $60 \mathrm{~mm}$ were cut out from the plate in the steel plants. The chemical composition was examined by a chemical elements spectral analyzer and is listed in Table 1 . It can be seen that the total oxygen content is only about $4 \mathrm{ppm}$ and the nitrogen content only about $19 \mathrm{ppm}$, indicating a very high metallurgical quality.

Table 1 Composition of $100 \mathrm{Cr} 6$ steel (wt.\%) 


\begin{tabular}{ccccccccc}
\hline $\mathrm{C}$ & $\mathrm{Si}$ & $\mathrm{Mn}$ & $\mathrm{P}$ & $\mathrm{S}$ & $\mathrm{Cr}$ & $\mathrm{Ti}$ & $\mathrm{N}$ & $\mathrm{O}$ \\
\hline 1.05 & 0.29 & 0.31 & 0.014 & 0.014 & 1.42 & 0.009 & $19 \mathrm{ppm}$ & $4 \mathrm{ppm}$ \\
\hline
\end{tabular}

The rods with a diameter of $60 \mathrm{~mm}$ were treated by a spheroidizing annealing by first heating up to $820^{\circ} \mathrm{C}$ and kept for 4 hours, then cooling to $720{ }^{\circ} \mathrm{C}$ and kept for 4 hours, and finally cooled down to room temperature. In order to reveal the effect of carburization on the RCF life, two different heat treatments were carried out on two groups of specimens, as shown in Fig. 1. 20 pieces of specimens were austenized at $840^{\circ} \mathrm{C}$ for half an hour and tempered at $170{ }^{\circ} \mathrm{C}$ for 3 hours after oil quenching, and these specimens are called conventionally heat-treated specimens (hereafter called $\mathrm{CH}$ bearing steel). The other 20 specimens were carburized at $950^{\circ} \mathrm{C}$ for about 6 hours in the vacuum carburizing furnace, stabilized at $840{ }^{\circ} \mathrm{C}$ for half hour, and then quenched into oil and finally tempered at $170^{\circ} \mathrm{C}$ for 3 hours, and these specimens are called surface-hardening-treated specimens (hereafter called SH bearing steel). The surface of all the specimens were ground and polished with sand abrasive papers with a grit of 1000 to unify the surface conditions by the same procedure and to reduce the surface roughness.

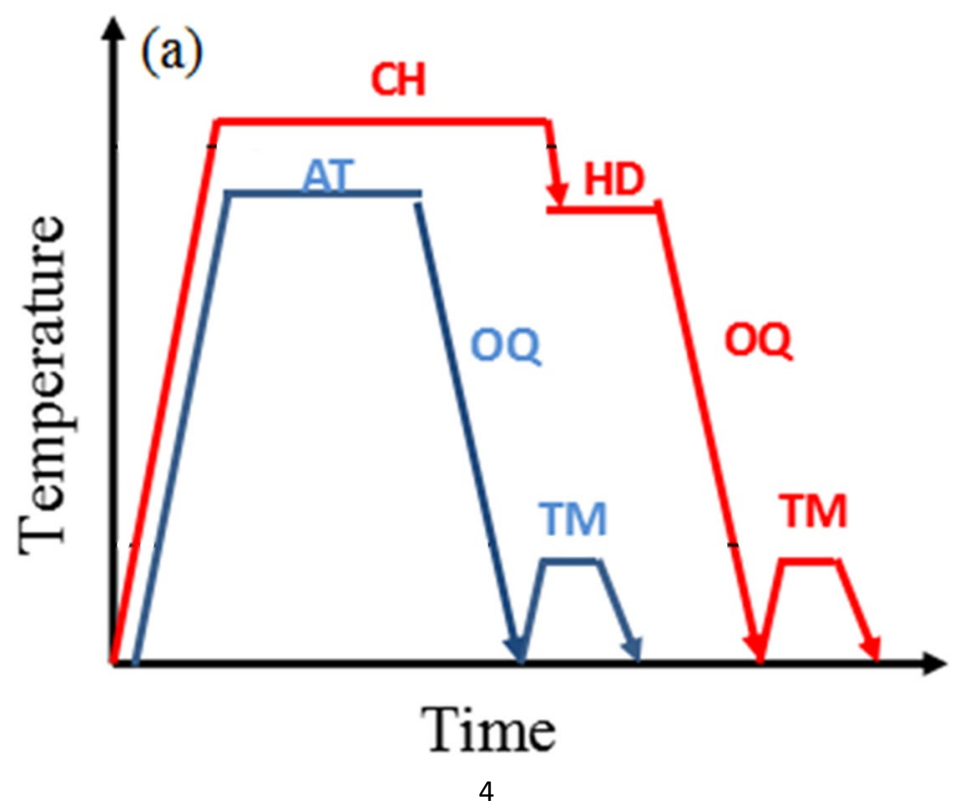


Figure 1. Sketch shows the conventional heat treatment and the surface hardening heat treatment of the high carbon bearing steel where AT represents austenite treatment, OQ oil quenching, TM tempering, $\mathrm{CH}$ carburization heat treatment and HD holding time for carbon diffusion.

The RCF tests were are carried out in a thrust rolling machine of TRF-1000/5-H with six balls rolled on the disc specimen along the load axis (see Fig. 2 for more details), and the tests were interrupted at $1 \times 10^{8}$ cycles. The RCF-life (number of cycles to failure) was recorded at room temperature with a maximum Hertzian stress of $4.5 \mathrm{GPa}$, a rotating speed of $1500 \mathrm{rpm}$ and well-controlled lubricating conditions. The RCF life of $\mathrm{L}_{10}$ is calculated at the failure probability of $10 \%$ according to the Weibull distribution between the failure probability of $\mathrm{P}(\mathrm{i})$ and the cycles to failure (N(i)), where the failure probability $\mathrm{P}(\mathrm{i})=\mathrm{i} /(\mathrm{k}+1)$ was calculated based on the rank number of $i$ in the ascending sequence of the cycles of the RCF and the total number of the samples test (k) [17]. Similarly, in order to explore the effect of carburization on the wear behaviors, specimens with and without carburization were examined by an OAT-U-HT2 (TKS company, Japan) wear machine to measure the frictional coefficient under a constant contact stress between the bulk specimens and the circular wear part.
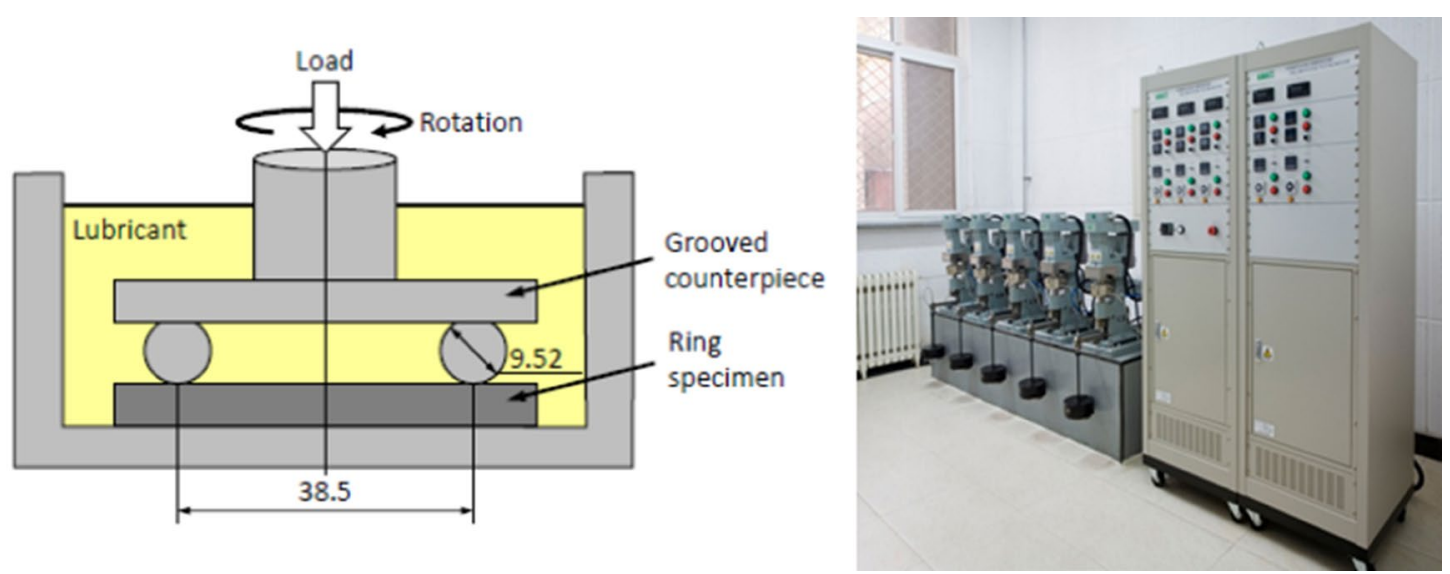

Figure 2. Sketch and picture show the set-up and the machine for the rolling contact 
fatigue.

The sample microstructure was characterized by optical microscopy and scanning electron microscopy (SEM), electron backscatter diffraction (EBSD) and X-ray diffraction (XRD). The details for sample preparation can be found elsewhere [18-22]. The Vickers microhardness, HV0.2, was measured using a Struers Durascan microindentor with a load of $200 \mathrm{~g}$.

\section{Results}

\subsection{Microstructure}

The microstructure of the $\mathrm{CH}$ bearing steel samples and the inner matrix microstructure of carburized SH bearing steel specimens are tempered martensite and retained austenite with submicron/micron-sized cementite particles, which can be found elsewhere [23]. So, the focus of microstructural characterization in the present study is the subsurface gradient structure of the SH carburized specimens. Fig. 3 shows the subsurface gradient microstructure and the hardness profile in the carburized SH specimen. The hardness profile shows the increase from around 680 HV0.2 in the matrix to 755 HV0.2 at the surface with the gradient thickness around $700 \mu \mathrm{m}$ in the carburized specimen. The plate/rod carbides (width: $1 \sim 20 \mu \mathrm{m}$; length: $15 \sim 65 \mu \mathrm{m})$ can be easily observed in the surface layer with a thickness around 500 $\mu \mathrm{m}$. The amount of these carbides decreases with the distance from the surface, in accordance with the microhardness profile. No plate/rod carbides can be found away from the surface region of the carburized specimens as shown in Fig. 3. 

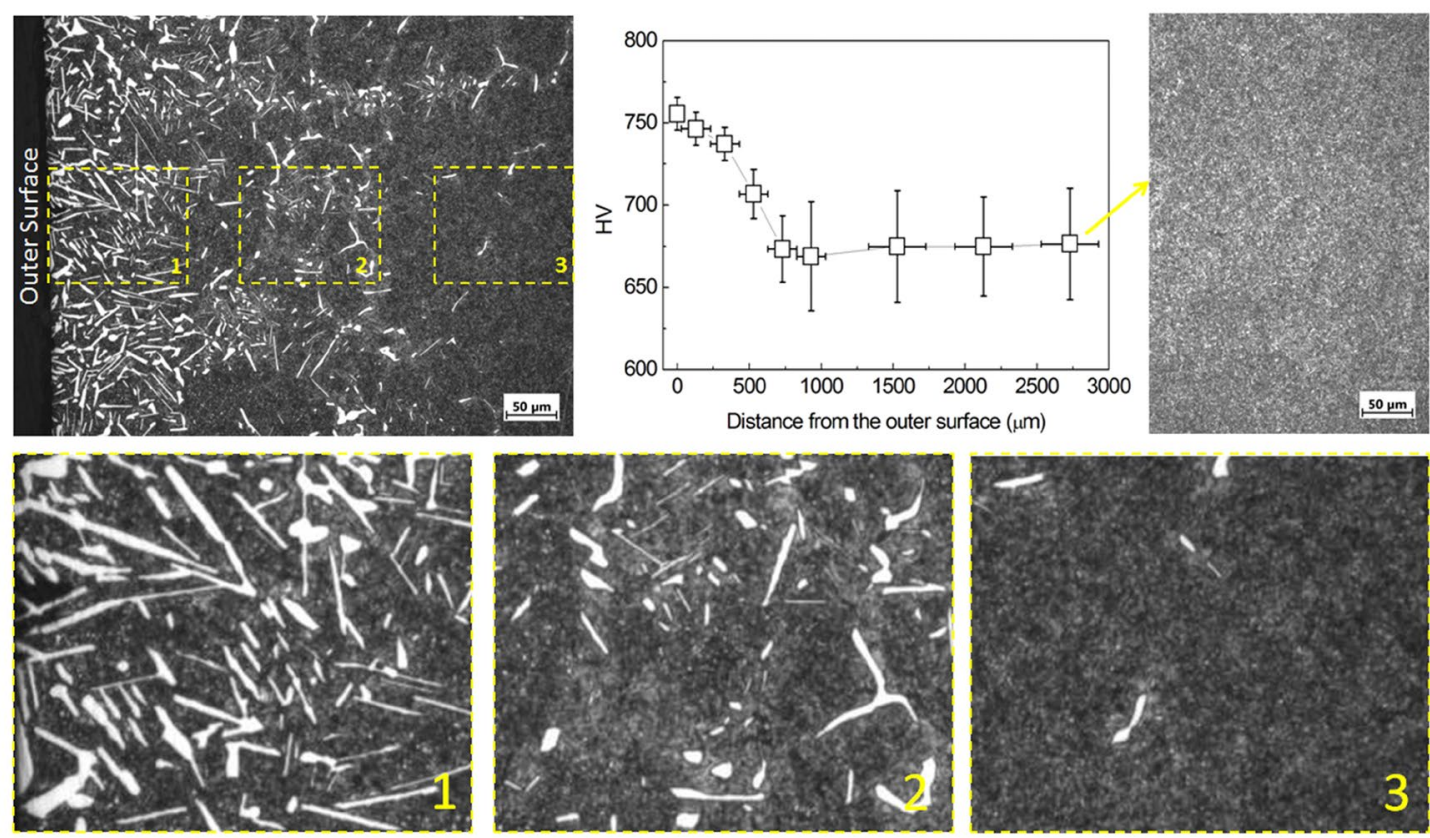

Figure 3. Micrographs and microhardness profile of the subsurface gradient structure of SH 100Cr6 bearing steel.

To identify these plate/rod carbides and the phases, XRD and EBSD have been used and the results are shown in Fig. 4. The volume fraction of retained austenite was identified by XRD as around $18 \%$ in the carburized surface layer and as about $20 \%$ in the matrix. The crystal structure of plate/rod carbides is characterized as $\mathrm{Fe}_{3} \mathrm{C}$ with orthorhombic structure by the HKL software with the NSD database (Fig. 4c and 4d). These carbides occupy around $30 \%$ of the area in the carburized surface with a thickness around $200 \mu \mathrm{m}$. It should be noted that the retained austenite is difficult to characterize by EBSD due to the fineness of the structure, so the combination of XRD and EBSD reveals the microstructure quite well. By comparing the XRD result on the content of retained austenite (18 vol.\%) with that in the EBSD map (Fig. 4d), it shows that most of the zero solution area is occupied by retained austenite. It should be noted that not only the high volume fraction of both retained austenite and carbide but the large micro-sized cementite characterizes the $\mathrm{SH}$ bearing steel specimens, which is 
significantly different from that of the specimens processed by conventional heat treatment ( $\mathrm{CH}$ bearing steel) [11].

(a)
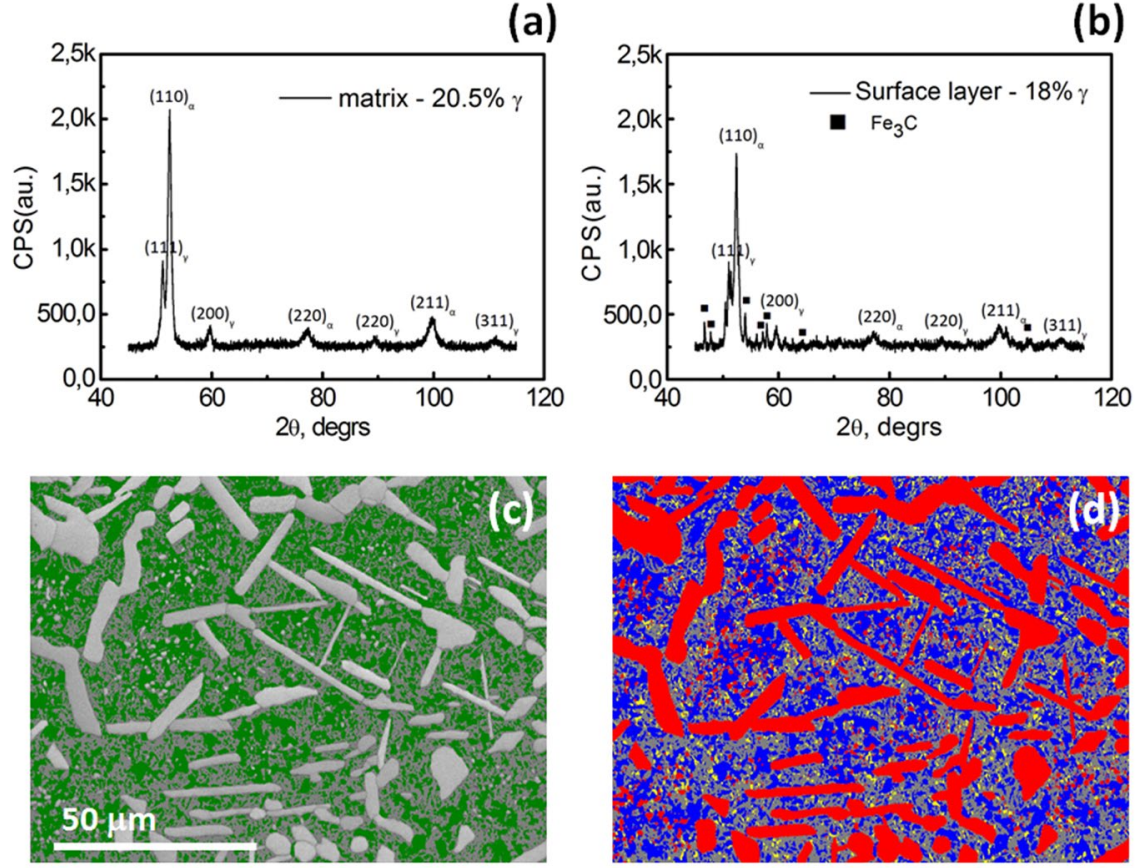

Figure 4. Microstructure and phase identification in the matrix and carburized surface layer by XRD (a and b) and EBSD (c and d). (c) and (d) show the same area in the carburized surface layer. The band contrast coloring for carbides is shown in (c). The phase coloring is applied in (d), where red represents $\mathrm{Fe}_{3} \mathrm{C}$ carbides, blue represents martensite and yellow represents austenite. The dark grey represents zero solution in (c) and (d).

\subsection{Wear and rolling contact fatigue properties}

Before testing the RCF properties, these two groups of specimens with conventional heat treatments $(\mathrm{CH})$ and with surface hardening treatments $(\mathrm{SH})$ were tested for wear properties with the focus on the starting process of the wear and the coefficient of friction (Fig. 5a). Although the stabilization process shows the similar characteristic after 10 seconds, differences can also be observed for these two types of specimens: the $\mathrm{CH}$ bearing steel has the average coefficient of friction around 0.50 with the fluctuation around 0.05 while the $\mathrm{SH}$ steel has the coefficient of friction around 0.48 
with the fluctuation around 0.01 . The smaller coefficient of friction and fluctuation may imply a smoother topography, which is consistent with the hardness, as reported elsewhere [24-27].

The rolling contact fatigue behaviors of the $\mathrm{CH}$ and $\mathrm{SH}$ bearing steel are shown in Fig. $5 b$ with the failure probability versus the cycle life. As it was shown in Fig. 5b, the rolling contact fatigue life, $\mathrm{L}_{10}$, of $\mathrm{CH}$ steel is about $1.0 \times 10^{7}$ cycles and only 4 out of 20 specimens did not fail after $10^{8}$ cycles. However, no failure of all the 20 specimens was observed in the SH steel processed by surface carburization. This means that for the $\mathrm{SH}$ bearing steel, the rolling contact fatigue life, $\mathrm{L}_{10}$, is at least $1 \times 10^{8}$ cycles, which is about 10 times higher than that of the $\mathrm{CH}$ bearing steel.
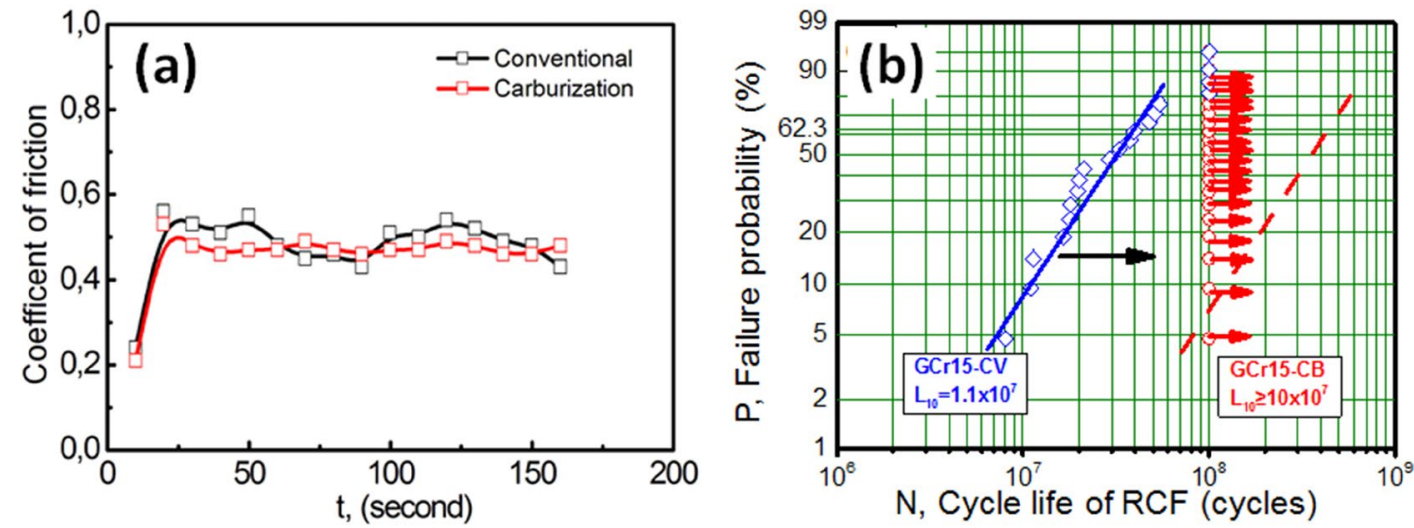

Figure 5. Coefficient of friction for wear testing and failure probability versus cycle life of rolling contact fatigue of the high carbon bearing steel processed by conventional $(\mathrm{CH})$ heat treatments and surface hardening $(\mathrm{SH})$ heat treatments.

\section{Discussions}

\subsection{Hardness increase by carburization}

The carburization of SH bearing steel has introduced a large volume of cementite in the surface layer. The hardness of this surface layer can be estimated by using the law of mixtures as following: 


$$
H V=H V_{\text {cementite }} \cdot V_{\text {cementite }}+H V_{\text {matrix }} \cdot\left(1-V_{\text {cementite }}\right)
$$

where $H V_{\text {cementite }}$ and $H V_{\text {matrix }}$ are the hardness of cementite (1040 HV [27]) and matrix

(680 HV as measured in this study as shown in Fig.2) respextively, and $V_{\text {cementite }}$ is the volume fraction of cementitie, measured as $30 \%$. This estimation gives the hardness around $788 \mathrm{HV}$, which is in good agreement with the measurement as shown in Fig. 3.

\subsection{Formation of large volume of carbides and retained austenite during carburization}

Compared with the conventional heat treatment, the carburization process during the surface hardening $(\mathrm{SH})$ heat treatments of the high carbon bearing steel introduces the interesting gradient microstructure with high content plate/rod of $\mathrm{Fe}_{3} \mathrm{C}$ carbides in the surface layer. The gradient microstructure consists of three areas: (i) Area A: the top surface area with a thickness of $200 \mu \mathrm{m}$ with a volume fraction of plate/rod $\mathrm{Fe}_{3} \mathrm{C}$ carbides around $30 \%$, (ii) Area B: the gradient area with a thickness around $500 \mu \mathrm{m}$ with decreasing volume fraction of plate/ $\mathrm{rod}_{\mathrm{Fe}} \mathrm{C}$ carbides with the distance from the surface and (iii) Area $\mathrm{C}$ : the inner matrix without plate/rod $\mathrm{Fe}_{3} \mathrm{C}$ carbides. It is quite interesting that the carbide shape, amount and distribution are completely different from the reported results of the carburized low carbon bearing steel [23]. Based on the observation that the volume fraction of plate/rod $\mathrm{Fe}_{3} \mathrm{C}$ carbides decreases with the distance from surface and diminishes in the center region, it should be related to the carbon content in the austenite at the carburizing temperature of $950^{\circ} \mathrm{C}$. A simple calculation based on the $\mathrm{Fe}-\mathrm{C}$ phase diagram in the thermal-calc software gives that the equilibrium carbon content in the austenite at $950^{\circ} \mathrm{C}$ is about $1.15 \mathrm{wt} . \%$ and that 
the total carbon content in Area A is around $2.78 \mathrm{wt} . \%$ taking into account $\sim 30$ vol.\% cementite. Thus the carburization and the excessive carbon content are the main reason for the formation of large volume plate/rod $\mathrm{Fe}_{3} \mathrm{C}$ carbides, which is supported by the fact that no such kind of $\mathrm{Fe}_{3} \mathrm{C}$ carbides form in the carburized layer of the low carbon bearing steel because the carbon content in the carburized layer of the low carbon bearing steel is usually less than $1.0 \mathrm{wt} . \%$ [28].

Not only the morphology but also the orientation of these plate/rod $\mathrm{Fe}_{3} \mathrm{C}$ carbides are quite different from the carbide network in the austenite grain boundary, which is usually found in the high carbon bearing steel. The orientation of the plate/rod cementite is usually parallel to each other, indicating a possible crystallographic growth characteristic. However, the detailed characterization and analysis of 3D morphology and the crystallographic orientation relationship of these cementite with austenite is for future investigation, with the focus on the forming mechanisms compared with Widmanstätten cementite in high carbon steels [29-33]

Apart from the large volume fraction of cementite, the retained austenite with a volume fraction around $20 \%$ is also found in both the carburized layer and the inner region, which is significantly higher than that of about $5 \%$ in the high carbon bearing steel processed by conventional heat treatment. This higher retained austenite could be interpreted by the high austenization temperature because the austenization temperature for the carburized $100 \mathrm{Cr} 6$ is the carburization temperature of $950^{\circ} \mathrm{C}$, which is significantly higher than that of $840{ }^{\circ} \mathrm{C}$ used in the conventional heat treatment (see Fig. 1). 


\subsection{Mechanism of enhanced rolling contact fatigue life of $100 \mathrm{Cr} 6$ bearing steel by carburization}

As shown in Fig. $5 \mathrm{~b}$, the rolling contact fatigue life $\left(\mathrm{L}_{10}\right)$ of the high carbon $\mathrm{SH}$ bearing steel is no less than $1 \times 10^{8}$ cycles, which is about 10 times higher than $\sim 1 \times$ $10^{7}$ cycles of the high carbon $\mathrm{CH}$ bearing steel. This large difference of the RCF life is inevitably related to the different surface hardness and the different microstructure resulted from the different heat treatments as the other conditions are the same. As it is observed from the microhardness measurements, the surface hardness of the $\mathrm{SH}$ bearing steel is about $755 \mathrm{Hv}(\sim 62.5 \mathrm{HRC})$, which is about $11 \%$ higher than that of the $\mathrm{CH}$ bearing steel, $680 \mathrm{Hv}(\sim 59.2 \mathrm{HRC})$. According to the contribution of increasing surface hardness to the RCF life, $31 \%$ increase of $\mathrm{L}_{10} \mathrm{RCF}$ life can be obtained through Eq. (1) [6], which is significantly smaller than 10 times enhancement of $\mathrm{L}_{10}$ as revealed in Fig. 4b. Thus only a minor role of the increased surface hardness on the enhanced fatigue life could be expected.

$$
\frac{L_{10}^{H R C 2}}{L_{10}^{H R C 1}}=\exp (0.1(H R C 2-H R C 1))
$$

where $L_{10}^{H R C 1}$ and $L_{10}^{H R C 1}$ is the RCF of L10 at surface hardness of HRC1 and HRC2, respectively.

Then the major reason for the improvement of the RCF life lies in the microstructure of the SH bearing steel. As it is shown in Fig. 2 and 3, the carbide volume fraction in the carburized surface layer is about $30 \%$ and the retained austenite volume fraction is about $20 \%$ as well, both of which are significantly higher than those in surface layer of the high carbon bearing steel processed by conventional heat treatment (less than 
10 vol.\% carbides and less 5 vol.\% retained austenite). Due to the brittle nature, the large volume fraction of the carbides in the carburized layer could be detrimental to the RCF life because the carbides could act as the origin of the crack [34]. However, this drawback can be overcome by the size, distribution and morphology and its combination with other microstructure as in the present surface. The plate/rod shaped cementite distributed in a separate way and did not form a network, at the same time they are coupled by the large volume fraction of retained austenite $(\sim 20$ vol. $\%)$ and martensite. As demonstrated in literature, the introduction of the retained austenite is beneficial to the rolling contact fatigue life because it may suppress the propagation of the crack during rolling contact fatigue test, and the maximum enhancement of the rolling contact fatigue life could be realized when the austenite volume fraction reaches $20-30 \%$, which could result in several times enhancement of rolling contact fatigue life $[12,35]$.

Apart from the contribution of the enhanced RCF life from the carbide and retained austenite developed by the carburization, the residue stress in the carburized surface could also be another reason to increase the RCF life. However, the nearly same austenite content both in the carburized layer and the inner part of the $\mathrm{SH}$ specimen imply that limited residual stress retained in the surface layer because of the similar phase transformation throughout the $\mathrm{SH}$ specimen. Thus it is believed that the enhancement of the rolling contact fatigue life is a combined contribution from both the large volume retained austenite and the large volume and distribution of micron-sized plate/rod cementite in the carburized high carbon bearing steel. 


\section{Conclusions}

In this study, the rolling contact fatigue life and the microstructure of the high carbon bearing steel of $100 \mathrm{Cr} 6$ are examined and compared after conventional heat treatment and carburization processing, separately. The main conclusions could be made as follows.

1. The rolling contact fatigue life is significantly enhanced from $1 \times 10^{7}$ cycles of $100 \mathrm{Cr} 6$ processed by the conventional heat treatment to at least $1 \times 10^{8}$ cycles treated by carburization, which provides a promising way to enhance the rolling contact fatigue life of the high carbon bearing steel.

2. Carburization of $100 \mathrm{Cr} 6$ introduces a gradient structure consisting of three areas: (i) Area A: the top surface area with a thickness of $200 \mu \mathrm{m}$ with a volume fraction of plate/rod $\mathrm{Fe}_{3} \mathrm{C}$ carbides around $30 \%$, (ii) Area B: the gradient area with a thickness around $500 \mu \mathrm{m}$ with decreasing volume fraction of plate/rod $\mathrm{Fe}_{3} \mathrm{C}$ carbides with the distance from the surface and (iii) Area C: the inner matrix without plate/rod $\mathrm{Fe}_{3} \mathrm{C}$ carbides.

3. The volume fraction of carbides (about 30 vol. $\%$ in the surface) and retained austenite $(\sim 20$ vol.\%), is significantly higher in the carburized steel than that processed by conventional heat treatment (less than 10 vol.\% carbides and less 5 vol.\% retained austenite)

4. The enhancement of the rolling contact fatigue life in the carburized high carbon bearing steel is ascribed to a combined effect of both the large volume retained austenite and the large volume and distribution of plate/rod cementite. 
Acknowledgements: This research was financially supported by both National Key R\&D Program of China (No. 2016YFB0300101) and National Natural Science Foundation of China (NSFC, No. 51871062 and 51371057). The authors thank Dr. B. Wang for his valuable inputs and discussion. X.Z. acknowledge support from the European Research Council (ERC) under the European Union Horizon 2020 research and innovation program (grant agreement No. 788567-M4D).

\section{References}

[1] M. Nagao, K. Hiraoka, Y. Unigame, Influence of nonmetallic inclusion size on rolling contact fatigue life in bearing steel. Sanyo Tech. Rep. 12 (2005) 38-45.

[2] T. Seki Evaluation of nonmetallic inclusions size by statistics of extreme value and prediction of fatigue life in bearing steels. Aichi Tech. Rep. 15 (1995) 24-29.

[3] Y. Chi, Z. Deng, M. Zhu, Effect of ladle usage on cleanliness of bearing steel. Metall. Mater. Trans. B 49 (2018) 440-450.

[4] M. Gafitanu, D. Nastase, S. Cretu et. al., Rolling bearings: design and technology, Volume 1,Technical Publishing House, Romania, 1985.

[5] C. Radu, It' s All About the Steel: the Importance of bearing steel cleanliness for long-life applications. RKB Technical Review, March 2011.

[6] E.V. Zaretsky, Rolling bearing steels: a technical and historical perspective. Materials Science and Technology 28 (2011) 58-69.

[7] T.V. Philip, New bearing steel beats speed and heat, Power Transmission Des. 28 (1986) 43-46.

[8] K.O. Lee, S.K. Hong, Y.K. Kang, H.J. Yoon, S.S. Kang, Grain refinement in bearing steels using a double-quenching heat-treatment process. Int. J. Automotive Technol. 10 (2009) 697-702.

[9] E.C. Santos, K. Kida, T. Honda, H. Koike, J. Rozwadowska Fatigue strength improvement of AISI52100 bearing steel by induction heating and repeated quenching. Mater. Sci. 47 (2012) 67-82.

[10] R. Padmanabhan, W.E. Wood, Microstructural analysis of a multistage heat-treated ultrahigh strength low alloy steel. Mater. Sci. Eng. 66 (1984) 125-143.

[11] Z. Cao, Z. Shi, F. Yu, K. Sugimoto, W. Cao, Y. Weng, Effects of double quenching on fatigue properties of high carbon bearing steel with extra-high purity. International Journal of Fatigue, 128 (2019) 105176.

[12] D. Zhu, F.-X. Wang, Q.-G. Cai, M.-X. Zheng, Y.-Q. Cheng, Effect of retained austenite on rolling element fatigue and its mechanisms. Wear, 105 (1985) 223-234.

[13] Z.N. Yang, Y.L. Ji, F.C. Zhang, M. Zhang, B. Nawaz, C.L. Zheng, Microstructural evolution and performance change of a carburized nanostructured bainitic bearing steel during rolling contact fatigue process. Mater. Sci. Eng. A, 725 (2018) 98-107.

[14] Z. Chen, T. Zhou, R. Zhao, H. Zhang, S. Lu, W. Yang, H. Zhou, Improved fatigue wear resistance of gray cast iron by localized laser carburizing. Mater. Sci. Eng. A, 644 (2015) 1-9.

[15] T. Noda, M. Okabe, S. Isobe, Hard surfacing of TiAl intermetallic compound by plasma carburization. Mater. Sci. Eng. A, 213 (2015) 157-161. 
[16] R.C. Dommarco, K.J. Kozaczek, P.C. Bastias, G.T. Hahn, C.A. Rubind, Residual stresses and retained austenite evolution in SAE 52100 steel under non-ideal rolling contact loading. Wear 257 (2004) 1081-1088.

[17] Z. Cao, Z. Shi, F. Yu, G. Wu, W. Cao, Y. Weng, A new proposed Weibull distribution of inclusion size and its correlation with rolling contact fatigue life of an extra clean bearing steel. International Journal of Fatigue 126 (2019) 1-5.

[18] G.H. Fan, Q.W. Wang, Y. Du, L. Geng, W. Hu, X. Zhang, Y.D. Huang, Producing laminated NiAl with bimodal distribution of grain size by solid-liquid reaction treatment. Mater. Sci. Eng. A 590 (2014) 318-322.

[19] S. Chen, J. Hu, X. Zhang, H. Dong, W. Cao, High Ductility and Toughness of a Micro-duplex Medium-Mn Steel in a Large Temperature Range from $-196{ }^{\circ} \mathrm{C}$ to $200{ }^{\circ}$ C. Journal of Iron and Steel Research International 22 (2015) 1126-1130.

[20] X. Zhang, A. Godfrey, G. Winther, N. Hansen, X. Huang, Plastic deformation of submicron-sized crystals studied by in-situ Kikuchi diffraction and dislocation imaging. Mater. Charac. 70 (2012) 21-27.

[21] X.D. Zhang, W. Liu, A. Godfrey, Q. Liu, The effect of long-time austenization on the wear resistance and thermal fatigue properties of a high-speed steel roll. Metall. Mater. Trans. A 40 (2009) 2171-2177.

[22] X. Zhang, C.V. Nielsen, N. Hansen, C.M.A. Silva, P.A.F. Martins, Local stress and strain in heterogeneously deformed aluminum: a comparison analysis by microhardness, electron microscopy and finite element modelling. Int. J. Plast. 115 (2019) 93-110.

[23] H.K.D.H. Bhadeshia, Steels for bearings. Prog. Mater. Sci. 57 (2012) 268-435.

[24] K. Monma, R. Maruta, T. Yamamoto, Y. Wakikado, Effect of particle sizes of carbides and amounts of undissolved carbide on the fatigue life of bearing steel. Journal of the Japan Institute of Metals 32 (1968) 1198-1204.

[25] C.A. Stickels, Rolling contact fatigue tests of 52100 bearing steel using a modified NASA ball test rig. Wear 98 (1984) 199-210.

[26] S. Das Bakshi, P.H. Shipway, H.K.D.H. Bhadeshia, Three-body abrasive wear of fine pearlite, nanostructured bainite and martensite. Wear 308 (2013) 46-53.

[27] X. Zhang, W. Liu, D. Sun, Y. Li, The transformation of carbides during austenization and its effect on the wear resistance of high speed steel rolls. Metall. Mater. Trans. A 38 (2007) 499-505.

[28] G. Krauss, Steels: Processing, Structure, and Performance. ASM International, 2005

[29] M.X. Zhang, P.M. Kelly, Crystalllography and morphology of Widmanstatten cementite in austenite. Acta Mater. 46 (1998) 4617-4628.

[30] W. Pistch, Acta metall. 10 (1962) 897.

[31] R.W. Heckel, J.H. Smith, H.W. Paxton, Trans. metall. Soc. A.I.M.E. 218 (1960) 566.

[32] D.S. Zhou, G.J. Shiflet, A new orientation relationship between austenite and cementite in an Fe-C-Mn steel. Scripta Metall. Mater. 27 (1992) 1215-1218.

[33] S.W. Thompson, P.R. Howell, The orientation relationship between intragranularly nucleated widmanstattin cementite and austenite in a commercial 
hypereutectold steel. Scripta Metall. 21 (1987) 1353-1357.

[34] E.V. Zaretsky, Rolling bearing and gear materials, in 'Tribology for aerospace applications', (ed. E.V. Zaretsky), STLE SP-37, 325-451; 1997, Society of Tribologists and Lubrication Engineers, Park Ridge, IL

[35] G.T.C. Ooi, S. Roy, S. Sundararajan, Investigating the effect of retained austenite and residual stress on rolling contact fatigue of carburized steel with XFEM and experimental approaches. Mater. Sci. Eng. A 732 (2018) 311-319 